\title{
Anatomy and the future: opportunities as translational science
}

\author{
Antonia Aránega \\ Department of Human Anatomy, University of Granada, E-mail: aranega@ugr.es \\ Spanish Association for the Advancement of Science
}

\section{SUMMARY}

Considerations are made on the development and future of Anatomy as a translational science, as well as the social impact it has had and has as a scientific discipline within the medical sciences. Throughout history, it has been possible to verify how Anatomy has been expanding its common borders with the rest of the medical disciplines, and how its scientific achievements show the close relationship between the development of society and scientific-technological progress. The progressive incorporation of modern study technologies into anatomical research has made it possible to broaden the field of exploration and diagnosis of diseases at the cellular, subcellular and macromolecular levels. With these considerations, I have also wanted to demonstrate the important work that translational anatomical research carries out in medical practice and, so that this work can be recognized in all its dimensions, including the social one.

Key words: Anatomical Research Translational Research in Anatomy-Translational Science

\section{COMMENTARY}

Over time, anatomical research has shown an abundant legacy of important contributions in basic and translational research, contributing, withitsscientificachievements, to thefundamental understanding of various pathologies and medicalsurgical approaches. Knowledge in general must influence the resolution of complex problems and the creative expansion of the frontiers of science (Domínguez-Franco et al., 2012).

In the last two decades, different analyses have indicated that anatomists in general had lagged behind in updating basic research compared to other disciplines of medicine. But it is also true that recently this situation has clearly changed: the research groups of the Anatomy departments, in a high percentage, have internalized and assumed the relevance of the usefulness of scientific achievements, assuming that translational research becomes possible when basic scientific achievements also have a clinical utility. These requirements are the key to the progress of translational research (Álvarez et al., 2014).

Evidence of this is the appearance in the area of Anatomy of new scientific journals such as Translational Research in Anatomy. This journal prioritizes translational research articles, and aims to disseminate the knowledge acquired in

Submitted: October 25, 2021. Accepted: November 12, 2021 
basic anatomical science to apply it to diagnosis and treatment of human pathology in order to improve the individual well-being of the patient. This new editorial strategy fosters the links between morphological research and medicine, so that they are strong and effective and that the collaboration between anatomical science and other areas is effective.

There are multiple pathologies that require different diagnostic and therapeutic solutions. These are demonstrative of the need for an interdisciplinary approach, where the role of anatomical knowledge is very important.

Basic researchers are paying much attention to translational approaches to their own research achievements to help, as far as possible, to overcome current and unresolved clinical problems.

Translational and interdisciplinary research is research that involves more than one discipline, where researchers from each area make contributions to a common research objective, integrating concepts and methodologies from their lines of research to reach new knowledge. This strategy has become an important component in shaping cutting-edge science and innovation (Arrizabalaga, 2021).

Advanced hospitals are based on multidisciplinary scientific and technical advances, because complex health care problems cannot be successfully addressed by a single discipline (Arguello et al., 2020).

For this reason, the strength of interdisciplinary research with strong and stable collaborations between the basic and clinical sciences and other disciplines, such as big data, physics and engineering, is an evident fact (Álvarez et al., 2021).

Even so, the training and professional qualification of physicians will continue to evolve, betting on much broader and more diverse interdisciplinary teams, focused on the value of sustained interdisciplinary research.

Throughout history, there are many examples of how anatomical knowledge has contributed effectively to advances in medical science: for example, the interface of the human prosthesis.

The human-prosthesis interface is one of the most complicated challenges facing the field of prosthetics. Its most important contributions are made in research and development by basic and clinical researchers around the world, Scientific achievements in the area of morphology have contributed to the understanding of the interface mechanics, favoring the design and evaluation of limb prostheses in general. It is high-quality, multidisciplinary research, much needed for advancements in the development of some bionic designs that have the potential for clinical application (Safari, 2020).

The contributions of different fields such as physics, materials sciences and mechanics are fundamental for the design of functional prostheses, although the researcher always requires an adequate qualification in anatomy, kinesiology, biomechanics and biology. The participations of engineering, artificial intelligence or electronics are contributing to a better understanding and manufacture of prosthetic mechanisms and pathomechanics.

Translational research has a bidirectional sense from basic research to patient-oriented research, and involves collaboration between scientists from multiple disciplines. Its current challenge is to find the relevant ways that allow to apply its research achievements to society (Rubio et al., 2010; Zarbin, 2020).

Modern regenerative medicine needs this translational concept of basic research, as it uses the principles and methods of basic science and engineering to promote the growth and regeneration of damaged tissues and viscera, or restore cell and tissue function.

Therefore, Translational Research in Anatomy should be useful not only to increase knowledge in general, but also as a communication and understanding platform between the discipline of anatomy and the rest of biomedical areas. 


\section{REFERENCES}

ÁLVAREZ P, BOULAIZ H, VÉLEZ C, RODRÍGUEZ-SERRANO F, ORTIZ R, MELGUIZO C, PRADOS J (2014) Qualitative and quantitative analyses of anatomists' research: evaluation of multidisciplinarity and trends in scientific production. Scientometrics, 98(1): 447-456.

ÁLVAREZ P, REYES M, ARGÜELLO A (2021) The management of scientific achievement in life sciences: a perspective from the complexity. Eur J Anat, 25(5): 615-624.

ARGÜELLO A, SOLANA VH, JÜRGENS B, ARÁNEGA P (2020) Patent analysis and territorial development: Example in the Biosanitary field. J Econ Bus Intellig, 2: 13-19.

ARRIZABALAGA J (2021) The challenge of (re)emerging diseases, the limits of the biomedical response and the new paradigm of global health. História, Ciências, Saúde-Manguinhos, 28(1): 255-281.

DOMÍNGUEZ-FRANCO A, GONZÁLEZ FJ, RODRÍGUEZ-LOSADA N, MARCHAL JA, CABRERA-BUENO F, CARRILLO E, PERÁN M, JIMÉNEZNAVARRO MF, ARÁNEGA A (2012) Factors influencing mobilisation of endothelial progenitor cells and angiogenic cytokines after an extensive acute myocardial infarction. Med Clin, 138(10): 415-421.

RUBIO DM, SCHOENBAUM EE, LEE LS, SCHTEINGART DE, MARANTZ PR, ANDERSON KE, ESPOSITO K (2010) Defining translational research: implications for training. Acad Med, 85(3): 470.

SAFARI R (2020) Lower limb prosthetic interfaces: Clinical and technological advancement and potential future direction. Prosthetics Orthotics Int, 44(6): 384-401.

ZARBIN M (2020) What constitutes translational research? Implications for the scope of translational vision science and technology. Transl Vis Sci Technol, 9(8): 22. 